\title{
O TEMPO, A IDADE E A PERMANÊNCIA NA ESCOLA: UM ESTUDO A PARTIR DOS LIVROS DE MATRÍCULA (RIO GRANDE DO SUL, 1895-1919) ${ }^{1}$
}

DOI: http://dx.doi.org/10.1590/2236-3459/50877

\author{
Natália de Lacerda Gil \\ Universidade Federal do Rio Grande do Sul, Brasil. \\ Joseane El Hawat \\ Universidade Federal do Rio Grande do Sul, Brasil.
}

Resumo

O presente artigo analisa um conjunto de livros de matrícula, produzidos no Rio Grande do Sul, entre os anos de 1895 e 1919, buscando compreender, pelos dados de preenchimento e pelas categorias adotadas para a identificação dos inscritos, a trajetória escolar dos alunos, as idades de ingresso e frequência e o tempo de permanência na escola. Pretendeu-se articular as disposições dos decretos relativos à instrução pública com os registros na documentação estudada. Intencionou-se, também, em alguma medida, colaborar na reflexão sobre as potencialidades e os limites da escrituração escolar como fontes que podem contribuir para a compreensão de aspectos da prática escolar e a experiência dos alunos no período indicado.

Palavras-chave: escrituração escolar, livros de matrícula, idade escolar.

\section{THE TIME, AGE AND PERMANENCE IN SCHOOL: A STUDY BASED ON THE BOOKS OF REGISTRATION (RIO GRANDE DO SUL, 1895-1919)}

\begin{abstract}
This paper analyzes a set of registration books, produced in Rio Grande do Sul, between the years 1895 and 1919, seeking to understand, by the analysis of the fulfilment and the categories adopted for identification of those enrolled, the school trajectory of students, ages of entrance, attendance and the time spent in school. It was also intended to relate the dispositions of decrees relating to public education to the records contained in the documentation. It was also purposed in
\end{abstract}

\footnotetext{
${ }^{1}$ Este trabalho vincula-se ao projeto interinstitucional Repetência e evasão na escola brasileira (1890-1930), financiado pelo CNPq.

ก. 46

Maio/ago., 2015 
some measure, to collaborate in the thinking about the potentialities and limits of school bookkeeping as sources that can contribute to the understanding of aspects of school practice and the student's experience in the mentioned period.

Keywords: school bookkeeping, books of registration, school age.

\section{EL TIEMPO, LA EDAD Y LA PERMANENCIA EN LA ESCUELA: UN ESTUDIO DE LOS LIBROS DE INSCRIPCIÓN (RIO GRANDE DO SUL, 1895-1919)}

\section{Resumen}

En este artículo se analiza un conjunto de libros de registro, que se produjeron en el estado de Rio Grande do Sul, entre los años 1895 y 1919, para tratar de comprender, por los datos asentados y las categorías adoptadas para la identificación de los alumnos, la trayectoria escolar de los estudiantes, la edad de entrada y la frecuencia y el tiempo de permanencia en la escuela. Hemos tratado de articular las disposiciones de los decretos relativos a la instrucción pública con los registros contenidos en la documentación estudiada. Intentamos, también, en cierta medida, colaborar en la reflexión sobre los puntos fuertes y las limitaciones de los registros escolares como fuentes que pueden contribuir a la comprensión de aspectos de las prácticas escolares y de la experiencia de los estudiantes en el período indicado.

Palabras-clave: escrituración escolar, libros de registro, edad escolar.

\section{LE TEMPS, L'AGE ET LE TEMPS PASSÉ À L'ÉCOLE: UNE ETUDE À PARTIR DES REGISTRES D'INSCRIPTION (RIO GRANDE DO SUL, 1895-1919)}

\section{Résumé}

Cet article analyse un ensemble de registres d'inscriptions scolaires, concernant l'état du Rio Grande do Sul, entre les années 1895 et 1919, et cherche à comprendre, d'après les données et les catégories retenues pour l'identification des étudiants, la trajectoire scolaire des élèves, l'âge de scolarisation et l'assiduité, ainsi que le temps passé à l'école. Nous avons cherché à approfondir les dispositions des décrets relatifs à l'instruction publique avec les registres figurant dans la documentation étudiée. Notre intention a également été, dans une certaine mesure, de participer à la réflexion sur les points forts et les limites des registres scolaires en tant que sources qui peuvent contribuer à la compréhension des aspects de la pratique scolaire et de l'expérience des élèves au cours de la période indiquée.

Mots-clé: livres d'école, livres d'enregistrement, d'âge scolaire. 
ste artigo traz à discussão análises sobre o movimento escolar, no que concerne à matrícula e permanência de alunos na escola no final do século 19 e início do século 20. O estudo concentrou-se no exame dos livros de matrícula de escolas isoladas, localizados no Arquivo Histórico do Rio Grande do Sul. Assim, inicialmente o texto se propõe a refletir sobre os limites e as possibilidades do uso da escrituração escolar como fonte para a História da Educação, buscando dialogar, nesse sentido, com alguns dos pesquisadores cujos trabalhos representam importante contribuição para o campo. Pretendeu-se, em seguida, apresentar as principais características do corpus documental, os livros de matrícula, observando sua materialidade e discutindo em que medida seu preenchimento seguia as prescrições legais. Por fim, objetivou-se delinear, a partir do exame minucioso dos registros presentes nesses documentos, algumas características da entrada na escola e das trajetórias escolares analisadas, sublinhando a dispersão da data da matrícula ao longo do ano, a multiplicidade de idades dos alunos e a predominância do curto tempo de permanência nas aulas públicas gaúchas no período considerado.

\section{Os suportes da escrituração escolar: considerações sobre seu uso como fonte histórica}

Mapas de frequência, livros de matrícula, livros de frequência, atas de exames, fichas de registro de matrícula, boletins de notas, registros de inspeção, atas de reuniões escolares, diários de classe, atestados de frequência, livros de ponto de professores, livros de registro de infrações disciplinares, diplomas. Estes são alguns dos suportes da escrita escolar que pretende organizar, fiscalizar, classificar e atestar as práticas de professores e alunos na escola. Nos séculos 19 e 20 essas escritas se diversificaram e especializaram, de modo concomitante e articulado ao processo pelo qual a própria escola foi imaginada, institucionalizada e expandida na sociedade brasileira.

Michel de Certeau afirma que na modernidade nossas sociedades organizam-se em torno de práticas escriturísticas. Nos últimos quatro séculos o escrever tornou-se uma prática mítica moderna: "O progresso é de tipo escriturístico. De modos os mais diversos, define-se portanto pela oralidade (ou como oralidade) aquilo de que uma prática legítima científica, política, escolar etc. - deve distinguir-se" (Certeau, 1994, p. 224). Ora, a escola moderna que se instaurou no Brasil durante o século 19 e que foi alçada a signo de progresso no projeto republicano, assumiu a prática escriturística como elemento fundamental. Nesta escola foi preciso que os aspectos relevantes sejam escritos e, cada vez mais, só é considerado importante o que está escrito. Essa produção escriturística se constituiu e consolidou a própria existência da escola, disciplinando as ações e relações, definindo as significações pertinentes. Certeau designa a escrita como "a atividade concreta que consiste, sobre um espaço próprio, a página, em construir um texto que tem poder sobre a exterioridade da qual ele foi previamente isolado" (1994, p. 225). Assim, segundo o autor,

o jogo escriturístico, produção de um sistema, espaço de formalização, tem como sentido remeter à realidade de que se distinguiu em vista de mudála. Tem como alvo uma eficácia social. Atua sobre a sua exterioridade. $\mathrm{O}$ laboratório da escritura tem como função estratégica: ou fazer que uma informação recebida da tradição ou de fora se encontre aí coligida, 
classificada, imbricada num sistema e, assim, transformada; ou fazer que as regras e os modelos elaborados neste lugar excepcional permitam agir sobre o meio e transformá-lo. (Certeau, 1994, p. 226)

Os livros de matrícula, como suportes destas práticas de escrita, integram o jogo descrito pelo autor, registram as informações recebidas de fora, o nome e a idade da criança, por exemplo, as classificam, as inserem num sistema escolar, transformando-as em aluno, em estudante lento ou inteligente, com desempenho satisfatório ou não.

Cabe ressaltar, portanto, a possibilidade de pensar a escrita escolar como uma prática docente que não se restringe ao ensinar a escrever, mas que remete àquilo que é registrado pelos professores para dar visibilidade às suas atividades, para atender às prescrições legais, para apoiar a memória. Diversos suportes de escrita vão povoar a escola moderna e se diversificar com o passar dos séculos. Os vestígios documentais dessas práticas escriturísticas podem ser construídos na pesquisa em História da Educação como fontes que nos permitem conhecer o trabalho docente, o alunado e algumas características dos percursos escolares, além de permitir compreender os modos de institucionalização da gestão escolar.

No século 19, no Brasil, a escola e o mestre frequentemente se confundem numa mesma imagem, visto que aquela era quase sempre constituída de apenas uma sala de aula, comandada por um único professor, que recebia alunos de diferentes idades e adiantamentos. Nessas circunstâncias, as tarefas de registro dos alunos matriculados, da frequência, dos desempenhos na aprendizagem são responsabilidade do professor. Conforme se avança no sentido de uma maior racionalização das práticas escolares, sobretudo ao longo do século 20 , aos poucos se assiste a dispersão dos registros em suportes variados. Do mesmo modo, com o incremento das práticas de inspeção e a implantação progressiva das escolas seriadas tem-se, cada vez mais, a distribuição das tarefas de escrituração entre diferentes trabalhadores do ensino - inspetores, diretores de escola, funcionários da secretaria das escolas, inspetores de alunos -, respondendo às necessidades de especialização das funções desempenhadas e de ampliação do controle sobre a prática docente.

Alguns estudos da área destacaram as potencialidades dessa documentação para a pesquisa em História da Educação ocupando-se, especificamente, dos mapas de frequência, que eram preenchidos mensalmente pelos professores para que as autoridades do ensino comprovassem o efetivo exercício docente. Desde pelo menos o início do século 19, ainda no âmbito das aulas régias, tem-se notícia de preenchimento nos "mapas, elaborados entre 1800 e 1821, de informações sobre o número de alunos, lugar de proveniência, faixa etária, condição social e ocupação profissional, aproveitamento, frequência e tempo de duração dos estudos" (Hilsdorf apud Vidal, 2008, p. 57). Tais fontes trazem elementos que permitem, pelo exame do historiador, caracterizar os indivíduos que frequentavam essas aulas. No entanto, como já se mencionou, estas escritas foram produzidas para outras finalidades.

Os mapas de frequência, bem como os livros de matrícula e de frequência, foram instituídos em várias províncias para permitir fiscalizar, por exemplo, a assiduidade de professores e alunos em resposta à determinação legal que atrelava a manutenção da escola e o pagamento do mestre a uma inscrição e frequência mínima de estudantes. Disso decorre que os professores públicos tenham mais amplamente se ocupado em 
produzir tais escritas e é possível supor certa profusão desses documentos, em termos proporcionais, de modo que uma parte deles foi preservada em arquivos públicos. $\mathrm{O}$ mesmo não ocorreu para as aulas particulares (Veiga, 2005), que quase sempre escapavam ao controle do Estado até pelo menos os anos 1930 e, portanto, podem não ter produzido esse tipo de escrituração ou não tê-la preservado. Por outro lado, como a manutenção das escolas e o pagamento dos professores dependia da quantidade de alunos registrados, é possível que muitas vezes esses números tenham sido superestimados $^{2}$. É ilustrativo, a esse propósito, o relato do presidente da Província de Minas Gerais em 1844:

Como pelas leis mineiras devem ser abolidas as escolas que não tiverem ao menos 24 discípulos, são obrigados os chefes de família a mandarem seus filhos às escolas; e tem os mestres gratificações além dos ordenados, segundo o número de discípulos que frequentam: tudo se arranja muito bem. Os pais matriculam os filhos, e não os mandam à escola; e os mestres enchem as suas relações de nomes de indivíduos que existem sim, mas que nunca lhes entram em casa, e põem-lhes os dias de frequência que bem lhes parece. Estes mapas vão às mãos dos delegados, que, em não sendo ativos e capazes de surpreenderem uma ou outra escola para lhes compararem o número de discípulos dos mapas com os que efetivamente encontrarem, tem que se guiar por informações, quando outras razões não tenham, só por não perderem o pobre do mestre escola, que é pai de família, dão os mapas por exatos, o governo manda pagar, e a lei fica iludida. (apud Veiga, 2005, p. 94)

A legislação estabelecia o que deveria estar registrado nesses mapas, cuja verificação era atribuição dos inspetores. No entanto, vários pesquisadores têm localizado registros que extrapolavam os definidos na prescrição legal (Veiga, 2005; Vidal, 2008; Dias, 2013). Diana Vidal, que analisou os mapas de frequência produzidos por dois professores na Província de São Paulo, nos períodos 1832-1842 e 1851-1862, ressalta que esses documentos são, ao mesmo tempo, instrumentos de gestão e de memória. Assim, respondem às exigências das autoridades superiores, mas também servem às considerações acerca dos alunos que os professores supõem necessário registrar. Em concordância com essas observações, Amália Dias, ocupando-se da análise de mapas de frequência, elaborados entre 1924 e 1949 no estado do Rio de Janeiro, acrescenta que "parte desses registros é obrigatória, outros acréscimos são recursos de comunicação utilizados pelos docentes" (2013, p. 16).

É preciso considerar, diante disso, que tais documentos permitem ver uma escrita sobre o outro, na medida em que se trata da caracterização dos alunos a partir do crivo dos professores ou pela legislação educacional. Desse modo, o que se tem, efetivamente, é a produção da criança como aluno a partir das categorias descritivas dos indivíduos que frequentam a escola que vão sendo inscritas nessa documentação institucional. Neste contexto, Cynthia Veiga lembra que

os diferentes saberes em profusão a partir de meados do século 19 sistematizaram uma condição de ser criança e de ter infância, e para isso

\footnotetext{
${ }^{2}$ É preciso destacar que a precariedade dos dados coligidos e o caráter lacunar das informações registradas são sempre mencionados seja nos relatórios contemporâneos aos registros aqui em discussão, seja pelos pesquisadores que têm examinado esses documentos. Hist. Educ. [Online] Porto Alegre v. 19 n. 46 Maio/ago., 2015 p. $19-40$
} 
diferentes normas se inscreveram no corpo da criança: ser bem comportada, obedecer, brincar, vestir roupas adequadas, frequentar a escola, ser bom aluno etc. Por meio da escola universalizou-se uma faixa etária atribuída ao tempo da infância, bem como uma nova maneira de as crianças se estabelecerem no mundo: como alunos(as). (Veiga, 2005, p. 78)

Essa escrita, que tem como um dos intuitos evidentes institucionalizar a escola, produz um saber sobre a escolarização. Um aspecto destacado nesse processo diz respeito ao modo como se constitui a experiência coletiva de ser professor. Segundo Vidal, é na articulação simbólica de práticas heterogêneas de uma sociedade que os professores preenchem

os mapas de frequência, renovando, nas estratégias de escrita, táticas de sobrevivência profissional, como a manutenção das escolas e o recebimento dos salários. Ao mesmo tempo, os mestres instalam práticas de classificação, ordenamento e hierarquização dos saberes e dos sujeitos escolares. (2008, p. 47)

Nesse sentido, importa perguntar como os professores traduziam as prescrições legais nas escritas burocráticas que produziam? Como inventaram a docência em articulação com as necessidades externa e interna desses registros? Tais questões revelam possibilidades de ampliação do conhecimento sobre a atuação dos professores recorrendo ao exame das fontes aqui em pauta. Contudo, nas pesquisas que desenvolvemos o interesse está focado nos alunos. É, portanto, buscando compreender quem eram os indivíduos que frequentavam as escolas, as características do percurso escolar que faziam e os desempenhos registrados que temos assumido a escrituração escolar como fonte.

\section{Os livros e de matrícula e o interesse em conhecer os alunos}

Os livros de matrícula, ao contrário dos mapas de frequência, não deveriam ser remetidos aos inspetores, embora estivesse previsto que fossem examinados nas visitas de inspeção. Correspondiam a um material da escola que deveria servir para registrar o movimento dos alunos na instituição para organização do próprio professor e oportuna conferência das autoridades. Segundo Diana Vidal, já em 1854, um decreto expedido pelo governo da Corte obrigava que

cada escola possuísse um livro de matrícula, contendo as faltas e o adiantamento de cada aluno anotados mensalmente até o dia em que o aluno saísse da escola, com declaração do motivo da saída; e que cada matrícula fosse efetuada mediante a presença de uma guia, na qual constasse o nome do pai, tutor, curador ou protetor do aluno, sua residência, estado e profissão, além da naturalidade, filiação e idade do aluno. (2008, p. 53)

Esse tipo de informação varia de um local a outro, de um período a outro, mas é frequentemente encontrado nos livros de matrícula, o que permite escrutinar as características sociais, econômicas e escolares dos alunos.

Parte dos elementos encontrados nos livros estava prescrita na legislação, correspondendo àquilo que as instâncias de gestão da educação consideravam 
necessário registrar. No entanto, como sublinhado anteriormente, a essas informações eram acrescidas outras, conforme as necessidades de registro percebidas pelos docentes. Assim, se por um lado, esses apontamentos permitem indiciar como as normas foram sendo apropriadas no âmbito das escolas, por outro, deixam vestígios de como as categorias "foram sendo inventadas pelos professores para organizar o universo da escola e para classificar e hierarquizar alunos e saberes" (Vidal, 2008, p. 53). Tais apontamentos reportavam ${ }^{3}$ à caracterização pessoal do aluno: idade, cor, condição de escravo, traços físicos, dente cariado, nacionalidade; à filiação: nome do pai, ocupação profissional, condição de analfabeto, nacionalidade; à moradia: endereço, condições da casa, telefone etc.; ao desempenho escolar: classe à qual pertence, se é inteligente, comportamento na escola, conteúdos escolares que já sabe. Ao registrarem informações dessa natureza, os livros de matrícula aportam, conforme afirma Diana Vidal, "indícios das condições sociais e econômicas das famílias e das relações que a escola com elas estabelece" (2008, p. 60).

A esse respeito cabe mencionar as possibilidades que eles abrem ao conhecimento e caracterização da população que, efetivamente, chegou à escola em cada período. Para além da verificação do contínuo aumento da quantidade das matrículas - aspecto marcante na escola brasileira, principalmente no século 20 - torna-se viável investigar quais grupos populacionais estão representados nas estatísticas de ampliação do acesso à escolarização. É o que fazem, por exemplo, Eliane Peres e Cynthia Veiga, examinando a escrituração escolar em trabalhos sobre a presença dos negros nas escolas. Cynthia Veiga encontra, nos mapas de frequência de Minas Gerais, no início do século 19, a informação da condição jurídica de escravo dos alunos. Ao analisar esses dados observa que é maior a presença de meninos escravos nas aulas particulares do que nas públicas. A autora acrescenta que,

não obstante, na Constituição e em toda legislação posterior não há nenhuma menção de proibição de escravos frequentarem mestres particulares. $O$ que foi reiterado permanentemente é a proibição de sua frequência a aulas públicas de professores providos pelo Estado (2005, p. 95)

Eliane Peres, por sua vez, examina os livros de matrícula do curso noturno da Biblioteca Pública Pelotense, que funcionou entre 1877 e 1915, pretendendo conhecer quem eram os alunos. Uma das questões formuladas pela autora referia-se ao pertencimento étnico-racial desses indivíduos. Como os livros não traziam registros a esse respeito, a autora recorreu ao expediente de "cruzar os dados disponíveis dos alunos com os de participantes em associações populares, especialmente as carnavalescas, dramáticas, abolicionistas, entidades de classe e, também, a imprensa produzida por negros" (2002, p. 78). Desse modo, evidencia a possibilidade efetiva da matrícula de negros no curso, alguns dos quais foram lideranças em Pelotas no período.

Assim, no que diz respeito à condição social dos alunos, tais registros contribuem para a identificação daqueles grupos para os quais a escola era uma possibilidade. Diana Vidal (2008) ressalta que o estudo detalhado dos sobrenomes dos alunos permitiria

\footnotetext{
${ }^{3}$ Está-se, especificamente, considerando o que vem sendo observado em livros de períodos muito distintos entre 1850 e 1950, no âmbito do grupo de pesquisa e pelas leituras das análises de outros pesquisadores. Vale lembrar que esses elementos não são todos localizados em um único livro. 
conhecer a procedência social desses indivíduos. Tal análise, conjugada à consideração do endereço, o conhecimento da ocupação territorial das cidades por diferentes grupos sociais e o cruzamento com os qualificativos atribuídos aos alunos pelos docentes - boa índole, foge às vezes, inteligente, nulo, etc. - pode ser reveladora das formas como as categorias de julgamento escolar são atravessadas por apreciações relativas ao pertencimento social (Bourdieu e Saint-Martin, 2012). Semelhante análise, levando-se em conta o gênero ou a idade, permitiria conhecer os diversos critérios que pautam a avaliação escolar.

Importa aqui investigar mais detidamente, a partir das trajetórias percorridas pelos indivíduos, aspectos da experiência escolar. Articulando as análises do movimento dos alunos na escola - os momentos de entrada na instituição, a obstrução dos fluxos, os tempos de aprendizagem - com as prescrições legais, pretendeu-se ampliar a compreensão do alcance social das práticas de escolarização. Os livros de matrícula aportam dados que não se equivalem, nem se restringem, aos localizados em outros documentos produzidos pela escola e pelos responsáveis pela gestão do ensino, mas é em articulação com eles que podem permitir melhor compreender aspectos da prática e da cultura escolar.

\section{Os livros de matrícula e frequência depositados no Arquivo Histórico do Rio Grande do Sul}

O preenchimento de livros de matrícula e frequência constituía-se em uma das atividades docentes no final do século 19 e início do século 20, representando uma importante parcela da escrituração escolar. Como as escolas no período frequentemente resumiam-se a um único professor ou professora, responsável pela totalidade das tarefas para o funcionamento das aulas, os registros feitos pelos docentes, devendo seguir as prescrições oficiais, permitem ver tanto a diligência, quanto as resistências no cumprimento dessas atribuições. Trazem indícios do desenvolvimento das práticas escolares, da racionalização dos tempos de aprender e da constituição e categorização do público infantil ao qual a escola se destina. Nesse sentido, conforme já se argumentou, os livros de matrícula e de frequência se constituem em fontes para a pesquisa em História da Educação que não devem ser desconsideradas.

Com a determinação de conhecer a escrituração das escolas públicas do Rio Grande do Sul, inicialmente entre 1889 e 1930, foram localizados livros com registros do ensino primário no Arquivo Histórico do Rio Grande do Sul - AHRS. Os livros encontrados pertencem, em sua maioria, às aulas públicas da região de Porto Alegre, concentrados na última década século 19 e nas duas primeiras do século 20.

Ao todo foram analisados vinte e nove livros, sendo vinte e dois livros de matrícula e sete de frequência. Os livros de matrícula eram utilizados para registrar os dados de identificação dos indivíduos inscritos a cada ano nas escolas. Traziam também informações sobre o grau de adiantamento e aproveitamento de cada aluno. Os livros de frequência, por sua vez, basicamente apontavam as presenças nas aulas, mediante uma tabela com o nome completo dos alunos e os dias letivos de cada mês.

Considerando o período em que tais documentos foram preenchidos e tendo em conta os possíveis deslocamentos dos mesmos até se constituírem como parte do acervo do AHRS, é de se destacar o bom estado de conservação do conjunto, o que permitiu o 
manuseio e a apreciação das informações que compunham cada volume. Com exceção de um exemplar, do qual foram destacadas as folhas dos meses finais, todos os outros estão íntegros.

É importante ressaltar que o conjunto considerado corresponde àquilo que, por motivos que desconhecemos, foi preservado e depositado no acervo do AHRS. Trata-se de uma coleção lacunar e dispersa no tempo que não pode ser tomada como representativa da totalidade das práticas de escrituração escolar no período ${ }^{4}$, embora seja uma fonte valiosa para compreendermos como se foi constituindo um modo de proceder à avaliação escolar, ao controle do fluxo dos alunos e à inspeção do trabalho docente.

A sequência de anos de um livro não necessariamente corresponde ao período total em que funcionou a escola. Por essa razão é preciso ter cautela nas análises sobre a duração da escolaridade, sobretudo para as matrículas feitas no último e no penúltimo ano de registro ${ }^{5}$. Também é verdade que a saída de um aluno pode não representar o término de sua escolaridade, assumida a hipótese de que ele tenha se transferido para outra escola. Consideradas essas limitações, a análise minuciosa do conjunto dos materiais tem permitido localizar alguns padrões no movimento escolar do período.

Do ponto de vista da materialidade, todos os volumes apresentam-se como cadernos grandes, com capa dura e pautados, onde os mestres realizavam o preenchimento manuscrito dos dados específicos de cada aluno. Observou-se que nos livros de frequência os docentes é que elaboravam manualmente as tabulações internas para o preenchimento, enquanto a maior parte dos livros de matrícula apresenta uma configuração interior previamente estabelecida. Ressalte-se que nos livros I213, I221, I222 as categorias vinham impressas no próprio livro.

Em relação ao período dos livros pesquisados, 18 deles possuem registros a respeito de matrículas efetuadas ao longo da década de 1910. Conforme o Relatório de instrução pública de 1912, contido no Relatório da Secretaria de Negócios do Interior e Exterior, o ensino público no início desse período era oferecido à população pelos seguintes estabelecimentos: escola complementar, colégios elementares e escolas isoladas $^{6}$. Dessas instituições, as escolas isoladas eram responsáveis pela maioria das matrículas (Gil, 2013).

Entre as escolas isoladas havia o que se chamava de aulas públicas, ou seja, escolas de apenas uma sala, providas de um único professor, funcionando em prédios adaptados e sob responsabilidade direta da administração do governo estadual. Os livros analisados referem-se todos a esse tipo de escola. Um aspecto a ser considerado sobre o conjunto de livros avaliados é que não há nenhum livro - de matrícula ou frequência - de escola seriada ${ }^{7}$.

Outra particularidade do material examinado é o predomínio das aulas mistas. No período em estudo o ensino público ofertado no Rio Grande do Sul poderia ser categorizado em três diferentes tipos: feminino, masculino e misto. A predominância de aulas mistas verificada não foge ao cenário da época, conforme se percebe nos dados

\footnotetext{
${ }^{4}$ É possível saber pelos relatórios da Instrução Pública que havia muito mais escolas em funcionamento no Estado do que livros depositados neste acervo.

${ }^{5}$ A pesquisa tem indicado que muito raramente a permanência na escola ultrapassava a três anos.

${ }^{6}$ Para o aprofundamento dessa questão ver Eliane Peres (2000).

${ }^{7}$ A localização de outros acervos e a possibilidade do estudo aprofundado dos registros da escola seriada é um dos objetivos propostos para as etapas seguintes da pesquisa.

\begin{tabular}{l|l|l|l|} 
Hist. Educ. [Online] & Porto Alegre & v. 19 & n. 46
\end{tabular}

\begin{tabular}{l|l} 
Maio/ago., 2015 \\
\hline
\end{tabular}

p. $19-40$
} 
gerais apresentados no relatório de 1912. Segundo esse relatório, das 1.197 aulas isoladas presentes no Rio Grande do Sul, 669 eram mistas, 437 delas eram masculinas e somente 91 exclusivamente femininas (Relatório, 1912, p. 194).

A classificação das escolas como mistas leva, inicialmente, a supor a convivência de meninas e meninos durante as aulas. Mas essa convivência não é necessariamente o que ocorre. No Capítulo I, do decreto n. 89, que trata do provimento e regime das escolas, tem-se que os grupos de alunos poderiam permanecer juntos ou separados:

Nas escolas mixtas a frequencia será simultanea, ou funccionará a aula duas vezes por dia, sendo uma para os alumnos do sexo masculino e outra para as do sexo feminino, se assim o exigir o numero d`elles ou a conveniencia do ensino, a juízo do respectivo inspector regional. (Decreto n. 89,1897 , art. 40)

Percebe-se que ao chamar uma aula pública de mista não estava descartada a possibilidade de meninos e meninas estudarem em turnos alternados, ficando a decisão final a critério do responsável pela inspeção regional à qual a respectiva escola era submetida.

As orientações do decreto n. 89, de 1897, partilham a responsabilidade da escrituração escolar entre os inspetores regionais, conselhos distritais e professores. Os inspetores regionais deviam realizar visitas trimestrais aos estabelecimentos de ensino de sua respectiva região. Dentre suas incumbências estava examinar com muita cautela a escrituração das escolas, avaliando a veracidade das matrículas e da frequência (art. 13, IV).

Nos casos em que houvesse uma ou mais escolas em uma região escolar, deveria ser criado o conselho distrital, formado por "cinco chefes de familia" que tivessem seus filhos estudando nas referidas escolas (art. 16). Nessa situação o conselho distrital tinha o compromisso de visitar e inspecionar mensalmente as escolas do seu distrito, onde deveriam avaliar cuidadosamente os livros de matrícula e frequência (art. 22, I, IV).

Quanto aos professores, estes deveriam "matricular os alumnos e proceder à escripturação da escola a seu cargo" (art. 67, 6º ), e com o conjunto destes dados elaborar e apresentar semestralmente ao inspetor regional um mapa contemplando a lista dos alunos matriculados, junto com a respectiva presença, idade, nacionalidade e aproveitamento (art. $67,12^{\circ}$ ). Cabe salientar que são esses registros que, mensalmente atestados pelo inspetor ou conselheiro distrital, validam o exercício do professor e viabilizam o recebimento de seu salário, além de fundamentarem a estatística escolar oficial do período (art. 90). Pode-se observar na legislação que se não fossem realizados os registros e organizados os mapas de frequência, o professor podia ser punido com a suspensão de exercício, e, consequentemente, de seus respectivos vencimentos no prazo de vinte a trinta dias. Havendo reincidência, o docente era removido da escola e, no caso de cumprir três penas de remoção, seria demitido (art. 67).

O preenchimento dos livros de matrícula segue categorias de identificação dos alunos que, embora sofram pequenas alterações de um livro a outro, apresentam elementos marcadamente estáveis. A análise desses elementos permite-nos ver de que modo se vai definindo o sujeito infantil no espaço escolar, ou seja, o aluno. Nos livros de matrícula em estudo, apesar de haver uma exigência por parte do poder público quanto ao preenchimento e à consequentemente inspeção desses documentos, foram 
constatadas algumas diferenças nas categorias utilizadas. Do conjunto em estudo, dois livros apresentaram as maiores alterações: o da Aula Mista do Arraial do Partenon (I211) e o da $43^{a}$ Aula Pública Mista do Passo do Dornelles (1227). No primeiro caso, a professora realizou a mudança do quadro de categorias em 1898, sendo incluídos campos para eliminação, aproveitamento e conduta. Tais inclusões, possivelmente, estariam vinculadas a uma adaptação da escrituração escolar às exigências do decreto $n$. 89, assinado no ano anterior (1897), e do Regimento interno dos estabelecimentos de ensino do Estado. Na segunda situação, o livro passou por sucessivas mudanças. Em 1910, com a chegada da professora Adelaide Rios e Silva, saem os campos de moradia e naturalidade e são criados os de aproveitamento e culto. Já em 1915, com a nova docente da aula pública, professora Ozoriolina da Silva, são incluídos campos para registro de comparecimentos, faltas, conduta e há uma modificação na estrutura da categoria das idades, separando em faixas etárias de 7 a 9, 10 a 12 e 13 a 14 anos, cada qual dividida pelo sexo, entre $\mathrm{Me} \mathrm{F}$.

Visualizando os 22 livros de matrículas e as categorias adotadas em cada um deles, encontramos uma estrutura similar em 14 aulas públicas, apresentando pequenas variações quanto à ordem das palavras, por exemplo, "anno, mez, dia" e "dia, mez, anno" na data da matrícula, mas, de maneira geral, a sequência de categorias é: número, nome, filiação, sexo e idades, nacionalidades, data da matrícula, frequência, eliminação, aproveitamento, conduta e observações. As demais acrescentam campos como religião ou culto (Aula Mista do Arraial do Partenon e Aula Mista do Caminho do Meio, respectivamente) ou moradia e moradia de cada um (Aula Pública Mista do Passo do Dornelles/Porto Alegre e Escola Mista São Roque, Garibaldi). Outra pequena diferença é a categoria dos números, sequência em que os alunos são matriculados. Nos livros da $12^{\text {a }}$ Aula Pública e da $4^{\text {a }}$ Aula Mista da Capital, apesar do título da coluna estar em branco, dos dados estão preenchidos em ordem de ingresso dos alunos.

Apesar de algumas diferenças de preenchimento e ainda que se leve em conta que a legislação especificava um mínimo de informações a serem coletadas, os livros analisados indicam os cinco conjuntos de dispositivos que Diana Vidal (2008) detalha em sua análise sobre os mapas de frequência de São Paulo. Também aqui os docentes mantinham a contabilidade: numeração de alunos, quantificação de faltas; a identificação: nome, idade, filiação; a gestão: registro de dia de matrícula, comprovação do início do trabalho docente e interrupções; a avaliação pedagógica: aproveitamento, e a avaliação social e comportamental: campos de conduta e observações.

\section{O tempo escolar, as idades de aprender e a permanência nas aulas}

Os livros permitem ver o lento processo de configuração de um tempo propriamente escolar. A definição da duração das aulas, dos períodos de descanso, das férias, assim como o estabelecimento de uma idade para se frequentar as aulas e de um momento para a matrícula dos alunos são elementos característicos da escola moderna que se impõem ao longo da primeira metade do século 20. Rita Gallego ressalta a historicidade desses aspectos ao lembrar que 
o tempo escolar, como um dos tempos sociais, também é diverso e plural. Consiste em um sistema social de referências temporais a partir do qual se definem, organizam e regulam o funcionamento, os ritmos, a coordenação e a sincronização das interações no interior da escola; assim, é fruto de uma construção cultural e pedagógica. (2003, p. 18)

A legislação da instrução pública, no Rio Grande do Sul, buscou disciplinar, em vários aspectos, as relações de inspetores, docentes, alunos e famílias com os tempos de aprender, obedecer, ensinar, avaliar, inspecionar. O decreto n. 89, de 1897, no art. 46, indicava que "no regimento interno serão estabelecidas as condições de matrícula, frequência, exercícios, escrituração e expediente das escolas". Quanto à matrícula, por exemplo, o regulamento define que a inscrição das crianças na escola pode ser feita desde o início do ano até setembro, ou seja, apenas três meses antes do encerramento do período letivo. Em vários dos livros analisados as matrículas iniciais aparecem concentradas nos primeiros meses do ano, de janeiro a abril. De qualquer modo, o que mais chama à atenção é o ingresso contínuo de alunos ao longo de praticamente o ano todo, quase sempre até a data limite estabelecia pela lei. No livro de matrícula da Aula Pública Masculina da Azenha (1219) aparece a anotação ao final dos registros de 1903: "Encerramos esta matrícula em 30 de setembro de 1903". Já no livro de matrícula da 37ª Aula Pública Mista da $1^{\text {a }}$ Região Escolar de Porto Alegre (I222) aparecem inscrições feitas em outubro, seguidas da anotação: "Encerrada em 31 de outubro de 1905". Fica evidente a importância, naquele momento, da definição da data limite para registro de novos alunos, o que se verifica, tanto pela legislação que tenta regular esse processo, quanto pela existência em alguns livros de anotação explícita quanto a isso. Percebe-se, também, que em alguns casos os registros indicam a desobediência da lei. Gallego salienta, em seu estudo sobre as escolas de São Paulo, que

se é verdade que muitas foram as maneiras encontradas pelo Estado para prescrever o modo ideal de organizar o tempo escolar, de modo particular a legislação, seja no âmbito do calendário seja no âmbito da distribuição diária do tempo, não é menos verdade que as prescrições quase sempre eram muito debatidas e questionadas não só pelos legisladores, mas, principalmente pelos inspetores, diretores, professores e pais; eram, inclusive burladas, de forma especial pelos professores. (2003, p. 27)

A desobediência à lei aparece no que se refere à idade dos indivíduos matriculados. Tem-se observado que são grandes as diferenças entre a prescrição legal e o registro localizado na escrituração escolar. As idades encontradas nos registros são mais variadas do que a determinação oficial. Embora a prescrição legal, em 1897, no Rio Grande do Sul, indicasse que "só serão admittidas á matrícula nas escolas públicas as crianças de 7 a 13 annos de idade" (decreto n. 89, art. 39), isso não significou a ausência nos livros de crianças com idades diferentes destas. Em 1906, o Regulamento da Instrução Pública, por intermédio do decreto $n$. 874, de 28 de fevereiro, procede a uma alteração que, no entanto, mantêm o impedimento da matrícula dos menores de sete anos: 
Não serão admittidos á matricula os menores de 7 annos, ficando ao prudente arbitrio do professor determinar a edade até a qual seja licito ao alumno frequentar a escola sem quebra da disciplina, nunca, porém além de 16 annos; salvo tratando-se de escolas mixtas, das quaes serão eliminados os alumnos logo que attingirem a edade de 12 annos. (Art. 91, $\left.\S 2^{\circ}\right)$

É possível encontrar, durante todo o período, crianças mais novas ou mais velhas do que previa o regulamento frequentando as escolas. Especialmente significativa é a matrícula de crianças de seis anos de idade, mas também é possível encontrar algumas de 5 anos e bem poucas de quatro. A idade de encerramento dos estudos é mais difícil de circunscrever, tanto na legislação, como se pode ver acima, quanto na prática escolar. Encontra-se, nos livros analisados, a presença de indivíduos de 14, 15 e 16 anos. É notável a progressiva diminuição da matrícula a partir dos 12 anos.

A discussão sobre a construção da idade escolar e de algumas das suas implicações sociais aponta, de fato, aspectos para os quais o exame dos livros de matrícula pode contribuir. Maria Cristina Gouveia ressalta que, no Brasil, as leis de obrigatoriedade escolar estabeleceram a faixa etária dos alunos correspondendo, aproximadamente, ao que Rousseau indicava como o período de realização das aprendizagens, ou seja, entre sete e 12 anos. Segundo a autora, no caso brasileiro,

o século 19 incorporou os discursos pedagógicos defensores da educabilidade da infância, do papel civilizatório da educação e, no interior dessa reflexão, da definição de um período ideal para a aquisição da instrução elementar. Nos oitocentos, essa cada vez mais foi compreendida como devendo se realizar nos espaços escolares. Era à criança no período da meninice, compreendida entre os 7 e 14 anos, que foram dirigidos os projetos de instrução pública. (2004, p. 275)

Os resultados da pesquisa com os livros de matrícula têm evidenciado, em concordância com a interpretação desta autora, como de outros, que o processo de definição da infância pela condição de aluno foi lento. Por um lado, vai demorar muito tempo ainda até que as crianças estejam efetivamente todas frequentando as aulas, por outro, chama a atenção o fato de que a concentração das idades dos matriculados indique uma faixa mais estreita do que a prevista em lei. Assim, para além da consideração das idades mencionadas na legislação, interessa sublinhar quais aquelas em que se concentram efetivamente as inscrições.

Pode-se notar que são mais frequentes nas escolas os indivíduos que têm entre 7 e 10 anos. A cada ano o percentual aproximado de alunos de cada idade segue a distribuição abaixo. 
Gráfico 1 -

Distribuição das idades nos registros de matrícula.

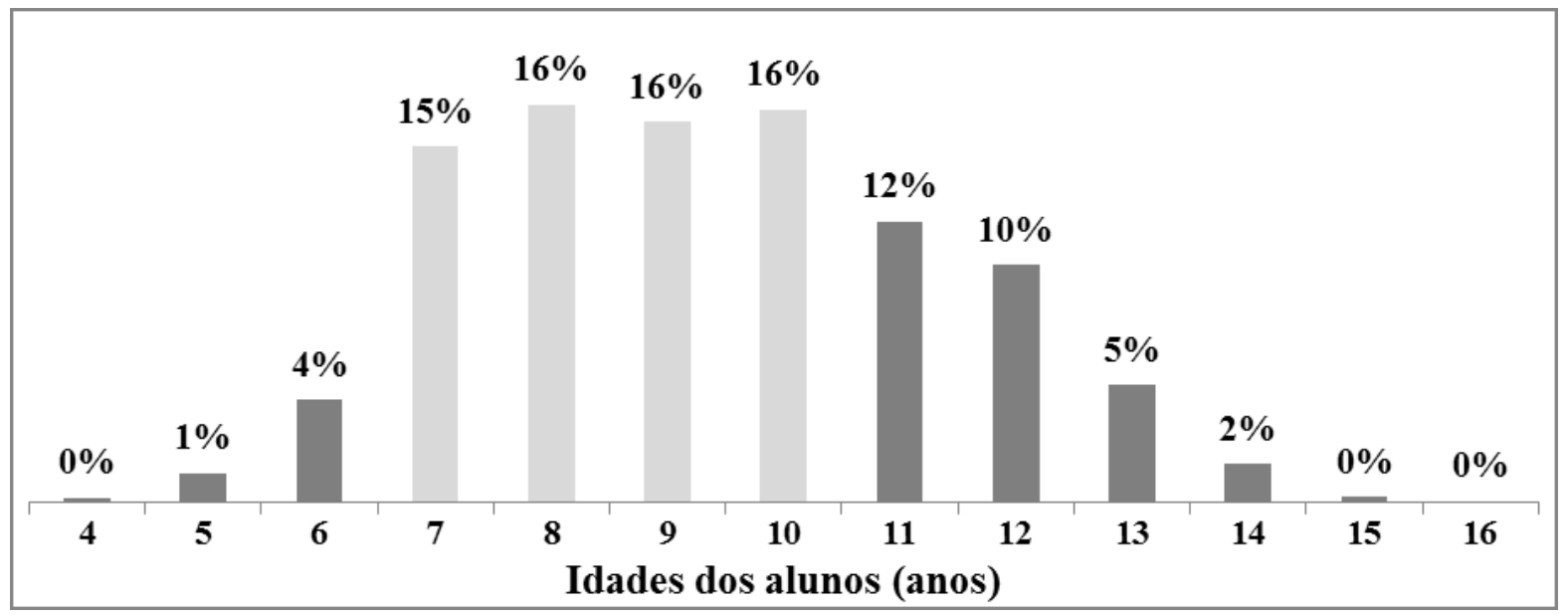

Assim, embora a legislação definisse a idade escolar como sendo dos sete aos 13 anos, vê-se que, no Rio Grande do Sul, efetivamente, a sociedade - ou seja, a família ou talvez mesmo o professor - considerava adequado encerrar antes disso o percurso escolar dos jovens.

A análise das idades em que efetivamente se encontram matriculados os alunos nos leva a pensar sobre as razões pelas quais os indivíduos deixavam de frequentar a escola. São fortes os indícios de que a definição acerca da conclusão da escolaridade esteja mais pautada nas expectativas das famílias e nos tempos de estudar usuais no período, bem como nas representações dos usuários acerca do que se devia aprender na escola, do que nas prescrições legais ou nos conhecimentos pedagógicos. Philippe Perrenoud ressalta, referindo-se ao caso europeu, que

nas primeiras escolas de gramática, nas primeiras universidades, nos primeiros colégios, os professores não pareciam se preocupar muito em avaliar as aprendizagens de seus alunos. Cabia a cada um avaliar suas próprias aprendizagens, comparando-se com os outros ou com os profissionais em exercício pelos quais tinha admiração, a começar pelo mestre. Ao aluno e à sua família cabia a responsabilidade de decidir se havia algum interesse espiritual ou algum ganho material em seguir uma aprendizagem, e em qual momento convinha abandoná-la, talvez para continuar com outro mestre. $(1984$, p. 83)

Nos livros de matrícula examinados existem espaços nos quais os professores deveriam indicar as razões e a data da retirada dos alunos da escola. Entre as categorias assinaladas na coluna destinada à Eliminação constam: morte, mudança, maioridade, curso completo, mau comportamento, sem declaração. Raramente, contudo, estas colunas aparecem preenchidas. Eventualmente surge a indicação da maioridade como causa da eliminação. É o caso do livro da $38^{a}$ aula de Porto Alegre (1228, 1910-1918) onde se tem esta como sendo a justificativa notificada para a saída de um aluno de 16 anos. O mesmo ocorre no livro da Aula Pública Masculina da Azenha (I219, 1902-1910). Estes registros coadunam-se com aquilo que regia a lei no período. 
A escassez de elementos instiga a avançar outras hipóteses acerca das definições para o início e o final da trajetória escolar no período. É possível supor a importância destacada de outros determinantes, que não a prescrição legal, tais como a idade dos irmãos e a percepção social e familiar de que a criança já havia aprendido o que era necessário ou de que não era capaz de aprender mais e melhor. Nesse sentido, temos acompanhado pelos livros de matrícula as idades em que os alunos deixam de frequentar o ensino primário tentando compreender quais as características desse movimento.

No livro de matrícula da Aula da Azenha (I211, 1895-1899) a idade de exclusão é marcadamente aos 13 anos. Nesta aparecem alguns poucos alunos de 14 anos e nenhum acima desta idade. Também é possível perceber que entre os alunos com percurso mais longo na escola - três, quatro ou cinco anos de escolaridade - é frequente que a idade no último ano seja 12, 13 ou 14 anos. Na aula mista da Azenha (I218, 19021906), nos 5 anos de registros, há apenas um aluno com 15 anos, sete com 14 anos e todos os outros com idade menor do que isso. No entanto, nesse livro existem alunos para os quais não aparece a indicação da idade. Na aula pública mista da Vila de Caxias (I217, 1901-1907) até 1907 é comum que no último ano de frequência às aulas os alunos tenham 13 anos, às vezes 12 e, destacadamente para aqueles que iniciam as trajetórias aos cinco ou seis anos, tenham 11 quando do encerramento do percurso. Nesse livro, há apenas cinco alunos de 14 anos e um único de 15 anos durante os nove anos cobertos pelos registros.

É importante salientar que há muitas inconsistências no preenchimento das idades na documentação analisada. Isso impede que se chegue a conclusões mais definitivas, mas não deixa de abrir pistas relevantes no sentido da compreensão das características da frequência à escola no período e local considerado. Há situações de erro evidente no preenchimento, visto que não é possível alguém ter idade menor do que já teve. É o que ocorre no livro 1211 (1895-1899), cujas anotações cobrem cinco anos de funcionamento da escola. Neste livro aparecem alguns poucos alunos de 14 anos, sobretudo nos primeiros anos de registro escolar, depois não se tem mais alunos acima dos 13 anos. Nesse sentido, é curioso notar que a aluna J. Rozada é registrada como tendo 13 anos em 1895, nos dois anos seguintes aparece com 14 anos e, em 1898, último ano em que frequenta essa aula pública, aparece novamente com 13 anos. Já nos livros I213 (18991904), I221 (1905-1910), I222 (1905-1911) a variação das idades registradas de uma mesma criança em diferentes anos é tão absurda que eles não puderam ser considerados nas análises que se seguem. Ocorre, por exemplo, que a criança V. da Cruz apareça com 10 anos em 1899, 9 anos em 1900, 11 em 1901, 12 em 1902 e 10 em 1903 (I213, 18991904).

Um dos aspectos característicos do período analisado, amplamente documentado nas fontes aqui consideradas, é o fato de que a matrícula de alunos novos podia ocorrer em qualquer idade, dentre as já mencionadas acima. A partir dos registros referentes à primeira matrícula, percebe-se uma sensível concentração da sua ocorrência entre os sete e 10 anos. Essa faixa etária representa cerca de $64 \%$ do total de apontamentos examinados. No quadro 1 se apresenta a idade dos alunos assinalada com maior frequência ${ }^{8}$ na data da primeira matrícula.

\footnotetext{
${ }^{8} \mathrm{O}$ quadro 1 apresenta as idades com maior ocorrência. Cabe reafirmar que nos registros dos livros de matrícula foram encontrados alunos com idade entre 4 e 16 anos na data da primeira matrícula.
Hist. Educ. [Online]
Porto Alegre
v. 19
n. 46
Maio/ago., 2015
p. $19-40$ 
Tabela 1 -

Idade dos alunos na primeira matrícula.

\begin{tabular}{l|c|c|c|c|c|c|c|c}
\hline $\begin{array}{l}\text { Primeira matrícula - } \\
\text { idade }\end{array}$ & 6 & 7 & 8 & 9 & 10 & 11 & 12 & 13 \\
\hline $\begin{array}{l}\text { Representatividade } \\
\text { da idade }\end{array}$ & $6 \%$ & $18 \%$ & $17 \%$ & $15 \%$ & $14 \%$ & $10 \%$ & $8 \%$ & $4 \%$ \\
\hline
\end{tabular}

Fonte: Arquivo Histórico do Rio Grande do Sul.

Os registros do livro de matrículas da Aula Pública Masculina da Azenha (I219, 1902-1910) apresentam, contudo, um movimento bem peculiar, que difere dos demais. Nessa escola, cujas informações cobrem o período de 1902 a 1910, é muito mais frequente que a primeira matrícula aconteça aos 11 anos. Dos 354 nomes registrados até 1907, apenas sete tinham seis anos de idade na primeira matrícula e 20 tinham 7 anos, enquanto que 61 deles tinham 11 anos. Nesse livro são, ainda, muito comuns às primeiras matrículas de alunos com 12, 13, 14 anos, o que não ocorre nos demais materiais analisados. Também chama a atenção que, apesar dos registros se estenderem por uma década, não existam trajetórias que ultrapassem 5 anos de frequência às aulas e que as mais longas, geralmente, nesse caso, limitem-se a três anos de escolaridade.

Em função do caráter lacunar da documentação examinada, não se pode afirmar, com segurança, que o primeiro registro de um aluno no livro de matrícula corresponda a seu início de escolarização, visto que ele poderia ter vindo de outra escola. É possível que isso tenha acontecido algumas vezes, embora não pareça adequado supor que a mudança de escola fosse uma constante no período. Tampouco é certo que o último registro observado represente o fim da escolaridade do aluno. A fim de avançar na compreensão dos padrões de início e fim da escolaridade, mostrou-se muito produtiva a análise da matrícula de grupos de irmãos, conferindo especial atenção às idades.

Nesse sentido, a análise do livro da Aula da Azenha (1211, 1895-1899) nos permite perceber movimentos relevantes. É possível notar uma tendência a matricular vários irmãos juntos no momento em que o menor chegasse a uma das idades em que era considerado possível frequentar a escola (5, 6,7 ou 8 anos). A compreensão do momento adequado para começar a escolarização, provavelmente, seguia mais as representações correntes no espaço social do que a definição legal. Para se ter uma ideia desse movimento, pode-se observar a idade dos seguintes grupos de irmãos cujas matrículas iniciais ocorreram ao mesmo tempo.

Quadro 2 -

Grupos de irmãos e suas respectivas idades na primeira matrícula.

\begin{tabular}{|c|c|c|c|}
\hline Ano da matrícula & Família & Aluno & Idade na primeira matrícula \\
\hline \multirow{4}{*}{1895} & \multirow{3}{*}{ Guerra } & P. & 10 \\
\cline { 3 - 4 } & & C. & 8 \\
\cline { 3 - 4 } & \multirow{4}{*}{ Mass } & J. & 7 \\
\cline { 2 - 4 } & & H. & 8 \\
\cline { 2 - 4 } & & V. & 8 \\
\cline { 3 - 4 } & &
\end{tabular}




\begin{tabular}{|c|c|c|c|}
\hline & & A. & 7 \\
\hline & & A. & 5 \\
\hline \multirow[t]{3}{*}{1896} & \multirow[t]{3}{*}{ Machado } & C. & 11 \\
\hline & & $\mathrm{L}$. & 8 \\
\hline & & I. & 7 \\
\hline \multirow[t]{9}{*}{1897} & \multirow[t]{3}{*}{ Araújo } & $\mathrm{R}$. & 10 \\
\hline & & $\mathrm{E}$. & 9 \\
\hline & & $\mathrm{R}$. & 8 \\
\hline & \multirow[t]{3}{*}{ Fortes } & A. & 13 \\
\hline & & M. & 7 \\
\hline & & G. & 6 \\
\hline & \multirow[t]{3}{*}{ Ribas } & A. & 11 \\
\hline & & A. & 9 \\
\hline & & J. & 6 \\
\hline
\end{tabular}

Fonte: Livro de matrícula da Aula da Azenha (I211, 1895-1899).

Há, certamente, exceções, como a situação de uma menina que é matriculada, em 1895, aos seis anos; no ano seguinte seu irmão é inscrito aos cinco, ou talvez quatro anos, visto que ele aparece como tendo cinco anos durante três anos seguidos, e, em 1898, mais um irmão é matriculado com seis ou sete anos.

Talvez mais importante do que o fato dos irmãos começarem a frequentar a escola todos juntos, é notar que era bastante comum que todos eles deixassem de frequentar a escola quando o mais velho tivesse 13 anos. É o caso de três irmãos que, em 1895, são matriculados juntos tendo sete, oito e 10 anos. Frequentam, juntos, a escola por três anos seguidos e deixam de frequentá-la ao mesmo tempo, coincidentemente quando o mais velho estava com 13 anos. Semelhante razão talvez explique também a matrícula de duas irmãs ao mesmo tempo, uma com nove e outra com 13 anos, que só frequentam a escola por um ano. Embora esses sejam casos muito frequentes na documentação, também aqui há exceções como, por exemplo, a situação de duas irmãs que são inscritas ao mesmo tempo, em 1895, uma delas com oito anos e a outra com 13. A mais velha fica na escola apenas um ano, enquanto a irmã mais nova frequenta a aula durante 5 anos $^{9}$.

A maior parte dos alunos, de fato, frequentava a escola por apenas um ou dois anos. A partir dos registros dos livros de matrícula pode-se observar que a curva de permanência cai bruscamente, tornando raros os alunos que frequentaram a mesma escola por três e quatro anos, e ainda mais raros os casos daqueles que permaneceram por mais de cinco anos.

\footnotetext{
${ }^{9}$ Nessas análises foram considerados irmãos os alunos com sobrenomes iguais cujos registros aparecem em sequência. Para os registros intercalados foram desconsiderados os sobrenomes mais comuns, tais como Oliveira, Silva e outros. Para confirmar as análises, em alguns casos, fez-se a conferência do nome do adulto responsável pela inscrição: pai, mãe ou tutor. Mesmo com esses cuidados não se pode excluir, por exemplo, a hipótese de serem primos.
} 
Gráfico 2 -

Tempo de permanência dos alunos.

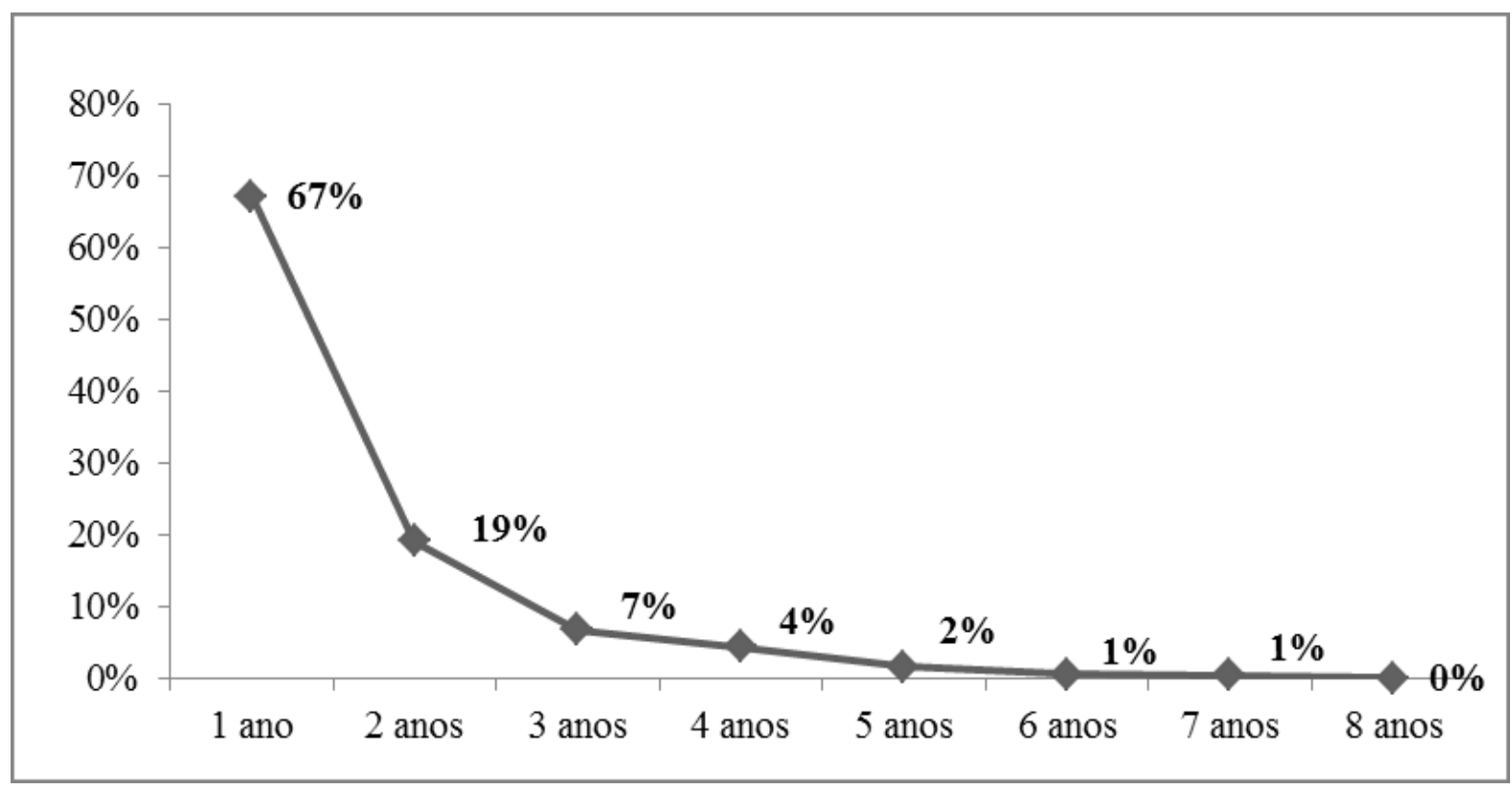

Fonte: Livros de matrícula - AHRS.

A respeito das mais longas permanências, no conjunto analisado, a $4^{a}$ Aula Pública Mista da Vila de Caxias foi a escola que concentrou o maior número de alunos que frequentaram por sete anos consecutivos uma mesma aula pública. De acordo com os registros de matrícula, no ano de 1901 foram inscritos os seguintes alunos: M. Bergazzo $(8 \text { anos })^{10}$, B. Bergazzo (6 anos), V. Milani (6 anos), A. Milani (6 anos), A. Bertoldo (8 anos), E. Viezo (8 anos), A. Viezo (6 anos), J. Esperanza (6 anos), M. Esperanza (7 anos), A. Zinanni (7 anos), E. Leonardi (7 anos), A. Mariani (10 anos) e A. Leonardi (5 anos). Este mesmo grupo manteve-se nas listas de crianças matriculadas nos anos seguintes até 1907. Já a única ocorrência localizada de permanência de 8 anos foi o caso de F. Zoldan, na Escola Mista São Roque, de Garibaldi. O aluno ingressou em 1904, com 6 anos de idade e manteve-se matriculado até o ano de 1911, com 12 anos.

A título de exemplo, vale observar a situação da aula pública da Azenha (I211, 18951899), onde dos 254 alunos inscritos nos cinco anos de funcionamento, entre 1895 e 1899, tem-se a seguinte distribuição quanto à permanência na mesma escola: 132 alunos a frequentaram apenas 1 ano, 63 alunos ficaram 2 anos, 29 alunos, 3 anos, 15 alunos, 4 anos, 11 alunos, 5 anos e 4 alunos estiveram ali por 6 anos. É possível afirmar que, frequentemente, os alunos que acumulam mais anos de escolaridade são aqueles que ingressaram mais novos. Assim, dos 7 alunos que estiveram matriculados 5 anos nesta escola, apenas um deles tinha mais do que 8 anos quando da primeira inscrição. 0 mesmo ocorre com os registros da 38 a Aula Mista do Caminho do Meio (I228, 1910-1918), que abrange de 1910 a 1918 e onde as trajetórias mais longas são de alunos que ficaram 6 anos matriculados ( 3 alunos) e 7 anos (3 alunos).

Estes 6 indivíduos tinham 8 anos ou menos quando da primeira matrícula. Situação semelhante é observada nos registros de mais dois livros de matrícula (I217, 1901-1907, e I214, 1899-1905). Interessa notar que essas observações coincidem com os resultados

${ }^{10}$ Entre parênteses está indicada a idade na matrícula inicial.

Hist. Educ. [Online] $\quad$ Porto Alegre

v. 19

ก. 46

Maio/ago., 2015

p. $19-40$ 
do estudo feito por Fernanda Rocha (2013), a partir de livros de matrícula do Grupo Escolar Paula Rocha, em Minas Gerais. A autora acompanhou a trajetória dos 25 alunos matriculados no $1^{\circ}$ ano primário em 1907 naquela instituição e pôde observar que "a maioria dos alunos mais velhos repetia menos vezes o $1^{\circ}$ ano primário, e a maioria dos alunos mais jovens repetia, duas, três ou mais vezes, o primeiro ano primário" (2013, p. 7). Embora a entrada na escola dos indivíduos jovens esteja relacionada, ao menos em algumas das escolas, às trajetórias mais longas, inscrever-se com pouca idade não é garantia de um longo percurso escolar. Como já se apontou acima, o mais recorrente é que os estudantes frequentassem as aulas por apenas um ou dois anos seguidos e isso significa que, para qualquer que seja a idade inicial de matrícula, as trajetórias são mais comumente curtas.

\section{Considerações finais}

É forçoso salientar que a matrícula e a permanência na escola não seguem, afinal, padrões muito estáveis. O que se procurou ressaltar são apenas algumas predominâncias ou características específicas circunscritas a um conjunto escasso de registros localizados. Elas, porém, aportam elementos significativos para avançar nas hipóteses sobre o que representou a experiência escolar para essas gerações. É possível imaginar que a atuação dos professores, responsáveis no período pela quase totalidade do trabalho de organização da escola e condução das aulas, tenha feito muita diferença na determinação das idades de estudar e dos tempos de permanência na escola.

Nesse sentido, a título de exemplo, vale considerar a observação do livro da $38^{a}$ Aula Mista do Caminho do Meio (I228, 1910-1918), onde são muitos os alunos que param de frequentar a escola por um ou dois anos e voltam a ser matriculados em seguida, frequentando-a por mais algum tempo. Uma possibilidade explicativa para esse movimento tão recorrente e que difere tanto do observado nos demais livros é que a professora insistisse com as famílias para que voltassem a inscrever seus filhos e os mantivessem na escola por um pouco mais de tempo. A confirmação, ou não, de hipóteses como esta implica a busca de outras fontes e o delineamento de novos focos para a continuidade das pesquisas. Instigar novas curiosidades e possibilidades investigativas não deixa, enfim, de ser um dos resultados pretendidos neste estudo.

\section{Referências}

BOURDIEU, Pierre; SAINT-MARTIN, Monique de. As categorias do juízo professoral. In: NOGUEIRA, Maria Alice; CATANI, Afrânio Mendes (orgs.). Escritos de educação. Petrópolis: Vozes, 2012, p. 185-216.

CERTEAU, Michel de. A invenção do cotidiano: 1 artes de fazer. Petrópolis: Vozes, 1994.

DIAS, Amália. Os mapas de frequência escolar e a produção dos serviços de fiscalização do ensino no Estado do Rio de Janeiro (1924-1949). Roteiro, Joaçaba, 2013, p. 13-40.

GALLEGO, Rita de Cássia. Usos do tempo: a organização das atividades de alunos e professores nas escolas primárias paulistas (1890-1929). São Paulo: USP, 2003. 189f. Dissertação (mestrado em Educação). Programa de Pós-Graduação em Educação, Universidade de São Paulo. 
GIL, Natália. As escolas isoladas no período de implantação do modelo escolar seriado no Rio Grande do Sul. ENCONTRO DA ASSOCIAÇÃOO SUL-RIO-GRANDENSE DE PESQUISADORES EM HISTÓRIA DA EDUCAÇÃO, 19, 2013. Anais ... Pelotas: Asphe, 2013.

GOUVEIA, Maria Cristina Soares de. Tempos de aprender: a produção histórica da idade escolar. Revista Brasileira de História da Educação, São Paulo, n. 8, 2004, p. 265-289.

LIVRO de Frequência da 19ª Aula Pública Mista, 1913-1914. AHRS, códice I166.

LIVRO de frequência da $38^{a}$ Aula Pública Mista de Porto Alegre, 1917-1918. AHRS, códice 1169.

LIVRO de frequência da Aula Pública Mista da Casa Branca e relação dos alunos matriculados, 1911-1914. AHRS, códice I163.

LIVRO de frequência dos Alunos da $43^{a}$ Aula Pública no Caminho do Meio, Porto Alegre, 1912-1915. AHRS, códice I165.

LIVRO de frequência dos alunos da Aula Pública Masculina da Azenha, Porto Alegre, 1902-1905. AHRS, códice I151.

LIVRO de frequência dos alunos da Aula Pública Masculina da Azenha, Porto Alegre, 1905-1908. AHRS, códice I150.

LIVRO de frequência dos alunos do Partenon, 1880-1884. AHRS, códice I140.

LIVRO de matrícula da 12a Aula Pública, 1911-1916. AHRS, códice I230.

LIVRO de matrícula da 19a Aula Pública Mista da Azenha, 1907-1912. AHRS, códice 1225.

LIVRO de matrícula da 25a Aula Mista de Navegantes, Porto Alegre, 1916-1917. AHRS, códice 1233.

LIVRO de matrícula da 29a Aula Mista do Passo da Mangueira, Porto Alegre, 1910-1919. AHRS, códice 1234.

LIVRO de matrícula da $29^{a}$ Aula Pública Mista da $1^{a}$ Região Escolar de Porto Alegre, 1905-1911. AHRS, códice 222.

LIVRO de matrícula da $37^{a}$ Aula Pública Mista da $1^{\text {a }}$ Região Escolar, Porto Alegre, 19051910. AHRS, códice I221.

LIVRO de matrícula da $38^{a}$ Aula Mista do Caminho do Meio entre Casa Branca e Capão da Fumaça, Porto Alegre, 1910-1918. AHRS, códice I228.

LIVRO de matrícula da $38^{a}$ Aula Mista do Caminho do Meio, Porto Alegre, 1906-1909. AHRS, códice 1224.

LIVRO de matrícula da 40ª Escola Pública, 1911. AHRS, códice I229.

LIVRO de matrícula da $43^{a}$ Aula Pública Mista do Passo do Dornelles, 1908-1918. AHRS, códice $\mathrm{I} 227$.

LIVRO de matrícula da $48^{a}$ Aula Pública Mista da $3^{\text {a }}$ Entrância, 1906-1908. AHRS, códice 1223.

LIVRO de matrícula da $4^{\text {a }}$ Aula Mista da Capital, 1913. AHRS, códice I232.

LIVRO de matrícula da $4^{a}$ Aula Mista do Arraial de São João, 1908-1912. AHRS, códice 1226.

LIVRO de matrícula da Aula da professora Acácia Ribeiro Gama, 1905-1910. AHRS, códice $\mathrm{I} 220$. 
LIVRO de matrícula da Aula Pública Masculina da Azenha, 1902-1910. AHRS, códice 1219.

LIVRO de matrícula da Aula Pública Mista da Azenha, 1902-1906. AHRS, códice I218.

LIVRO de matrículas da 26a Aula Mista da Capital, 1899-1905. AHRS, códice 1214.

LIVRO de matrículas da $4^{a}$ Aula Pública Feminina em São Pedro de Alcântara, Torres, 1900-1903. AHRS, códice I215.

LIVRO de matrículas da $4^{a}$ Aula Pública Mista Efetiva da $3^{a}$ Légua da Vila de Caxias, 1901-1907. AHRS, códice 1217.

LIVRO de matrículas da Aula Pública Mista da Profa. M. Innocência C. e Silva, Porto Alegre, 1899-1904. AHRS, códice 1213.

LIVRO de matrículas da Escola Mista São Roque, Garibaldi, 1900-1911. AHRS, códice 1216.

LIVRO de matrículas dos alunos da Aula Mista do Arraial do Partenon, 1895-1899. AHRS, códice 1211.

PERES, Eliane Teresinha. Aprendendo formas de pensar, de sentir e de agir: a escola como oficina da vida - discursos pedagógicos e práticas escolares da escola pública primária gaúcha (1909-1959). Belo Horizonte: UFMG, 2000. 493f. Tese (doutorado em Educação). Programa de Pós-Graduação em Educação, Universidade Federal de Minas Gerais.

PERES, Eliane Teresinha. Sob(re) o silêncio das fontes: a trajetória de uma pesquisa em história da educação e o tratamento das questões étnico-raciais. Revista Brasileira de História da Educação, São Paulo, n. 4, 2002, p. 75-102.

PERRENOUD, Philippe. La fabrication de l'excellence scolaire: du curriculum aux pratiques d'évaluation. Genebra: Librairie Droz, 1984.

RELATÓRIO apresentado ao Exmo. Sr. Dr. Carlos Barbosa Gonçalves, Presidente do Estado do Rio Grande do Sul, pelo Dr. Protasio Antonio Alves, Secretário de Estado dos Negócios do Interior e Exterior, em 9 de setembro de 1912. Porto Alegre: Officinas Graphicas da Livraria do Globo. 1912.

RIO GRANDE DO SUL. Decreto n. 874, de 28 de fevereiro de 1906. Reorganisa a instrucção publica do Estado. Leis, decretos e actos do governo do Estado do Rio Grande do Sul de 1906. Porto Alegre: Officinas Typographicas d'O Independente, 1912.

RIO GRANDE DO SUL. Decreto n. 89, de 2 de fevereiro de 1897. Reorganisa a instrucção primaria do Estado. Leis, decretos e actos do governo do Estado do Rio Grande do Sul de 1906. Porto Alegre: Officinas Typogr. de Echenique Irmãos \& Cia, 1907.

ROCHA, Fernanda Cristina Campos da. Trajetória de alunos em um grupo escolar mineiro, entre 1907 e 1916: o tema da repetência escolar. CONGRESSO BRASILEIRO DE HISTÓRIA DA EDUCAÇÃO, 7, 2013. Anais ... Cuiabá: UFMT/SBHE, 2013.

SOUZA, Cynthia Pereira de. A criança-aluno transformada em números (1890-1960). In: STEPHANOU, Maria; BASTOS, Maria Helena Camara (orgs.). Histórias e memórias da educação no Brasil. Petrópolis: Vozes, 2005, p. 195-208.

SOUZA, Rosa Fátima de. Templos de civilização: a implantação da escola primária graduada no Estado de São Paulo. São Paulo: Unesp, 1998.

VEIGA, Cynthia Greive. A produção da infância nas operações escriturísticas da administração da instrução elementar no século 19. Revista Brasileira de História da Educação, São Paulo, n. 9, 2005, p. 73-108. 
VIDAL, Diana Gonçalves. Mapas de frequência a escola de primeiras letras. Revista Brasileira de História da Educação, n. 17, 2008, p. 41-67.

NATÁLIA GIL é professora de História na Educação na Universidade Federal do Rio Grande do Sul. Doutora em Educação pela Universidade de São Paulo, coordena a pesquisa Repetência e evasão na escola brasileira (1889-1930), financiada pelo CNPq.

Endereço: Rua Paulo Gama, 110 - Faculdade de Educação - sala 1005 - 90046-900 Porto Alegre - RS - Brasil.

E-mail: natalia.gil@uol.com.br.

JOSEANE EL HAWAT é estudante no Programa de Pós-Graduação em Educação da Universidade Federal do Rio Grande do Sul, onde pesquisa a avaliação em matemática nas escolas isoladas de Porto Alegre (1873-1919).

Endereço: Rua Cipó, 730/120 - 91360370 - Porto Alegre - RS - Brasil.

E-mail: joseaneh@yahoo.com.br.

Recebido em 13 de outubro de 2014.

Aceito em 7 de janeiro de 2015. 